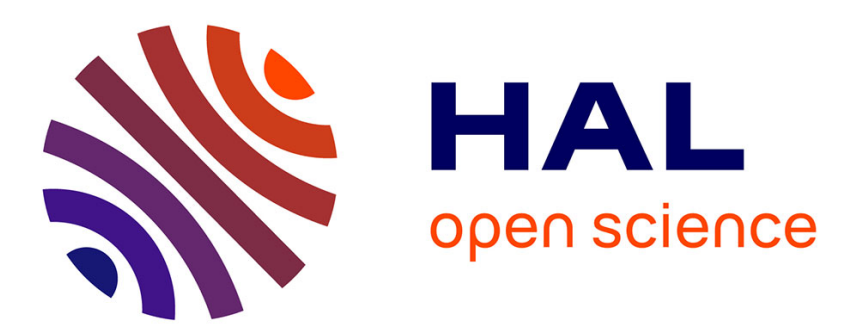

\title{
Asymmetric Synthesis of Enantiopure Pyrrolidines by C(sp 3 )-H Amination of Hydrocarbons
}

Yanis Lazib, Pascal Retailleau, Tanguy Saget, Benjamin Darses, Philippe Dauban

\section{- To cite this version:}

Yanis Lazib, Pascal Retailleau, Tanguy Saget, Benjamin Darses, Philippe Dauban. Asymmetric Synthesis of Enantiopure Pyrrolidines by C(sp 3 )-H Amination of Hydrocarbons. Angewandte Chemie International Edition, 2021, 10.1002/ange.202107898 . hal-03344954

\section{HAL Id: hal-03344954 \\ https://hal.science/hal-03344954}

Submitted on 15 Sep 2021

HAL is a multi-disciplinary open access archive for the deposit and dissemination of scientific research documents, whether they are published or not. The documents may come from teaching and research institutions in France or abroad, or from public or private research centers.
L'archive ouverte pluridisciplinaire HAL, est destinée au dépôt et à la diffusion de documents scientifiques de niveau recherche, publiés ou non, émanant des établissements d'enseignement et de recherche français ou étrangers, des laboratoires publics ou privés. 


\title{
Asymmetric Synthesis of Enantiopure Pyrrolidines by C(sp $\left.{ }^{3}\right)-H$ Amination of Hydrocarbons
}

Yanis Lazib, ${ }^{a}$ Pascal Retailleau, ${ }^{a}$ Tanguy Saget, ${ }^{[*], a}$ Benjamin Darses, ${ }^{[*], a, b}$ and Philippe Dauban ${ }^{[*], a}$

In memory of Viktor Snieckus, a truly creative and enthusiastic chemist

[a] Y. Lazib, Dr. P. Retailleau, Dr. T. Saget, Dr. B. Darses, Dr. P. Dauban Université Paris-Saclay, CNRS, Institut de Chimie des Substances Naturelles, UPR 2301, Av. de la Terrasse, 91198 Gif-sur-Yvette, France E-mail: philippe.dauban@cnrs.fr ; tanguy.saget@cnrs.fr

[b] Dr. B. Darses Université Grenoble Alpes, Département de Chimie Moléculaire, CNRS UMR-5250, 38058 Grenoble (France)

E-mail: benjamin.darses@univ-grenoble-alpes.fr

\begin{abstract}
The asymmetric synthesis of enantiopure pyrrolidines is reported via a streamlined strategy relying on two sequential $\mathrm{C}-\mathrm{H}$ functionalizations of simple hydrocarbons. The first step is a regio- and stereoselective catalytic nitrene $\mathrm{C}-\mathrm{H}$ insertion. Then, a subsequent diastereoselective cyclization involving a 1,5-Hydrogen Atom Transfer (HAT) from a N-centered radical leads to the formation of pyrrolidines that can then be converted to their free $\mathrm{NH}$-derivatives.
\end{abstract}




\section{Main text}

Pyrrolidines are synthetic targets of choice for organic chemists. ${ }^{[1]}$ 2,5-Substituted derivatives, particularly, are important motifs with relevant applications in many areas of chemistry. In addition to be at the core of the recently approved antiviral Ombistavir 1 (Figure 1), ${ }^{[2]}$ they are privileged scaffolds in asymmetric catalysis. For example, they have been used as $C_{2}$-symmetrical ligands for metal complexes $2,{ }^{[3]}$ organocatalysts $3,{ }^{[4]}$ or chiral auxiliaries $4 .^{[5]}$ This paramount importance has translated to the design of innovative methods for the synthesis of pyrrolidines, ${ }^{[6]}$ including stereoselective methods based on enantioselective functional group transformations. ${ }^{[7,8]}$

\section{Figure 1.}

The emergence of catalytic $\mathrm{C}-\mathrm{H}$ functionalization reactions in the last twenty years has revolutionized the art of retrosynthesis. $\mathrm{C}-\mathrm{H}$ bonds are now considered as functional groups that allow the conception of efficient synthetic strategies with improved step- and atom-economy. ${ }^{[9]}$ This new paradigm in organic synthesis has found applications in heterocyclic chemistry with the use of new bond disconnections for the synthesis of nitrogen heterocycles. ${ }^{[10]}$ With respect of pyrrolidines, three main strategies have been developed for their preparation (Scheme 1a). Daugulis and Chen first reported the application of $\mathrm{C}-\mathrm{H}$ activation reactions to the formation of pyrrolidines. The latter involves a catalytic $\mathrm{C}-\mathrm{H} / \mathrm{N}-\mathrm{H}$ coupling via a concerted metallation-deprotonation process that mainly occurs at primary $\mathrm{C}-\mathrm{H}$ bonds. ${ }^{[11]}$ Inspired by the Hofmann-Löffler-Freytag reaction, ${ }^{[12]}$ stoichiometric approaches relying on intramolecular H-atom transfer have been designed. Because the 1,5-pathway is highly favored, the formation of pyrrolidines via the intermediacy of $N$-centered radicals is often exclusively observed. ${ }^{[13]}$ The last strategy is based on metal-catalyzed intramolecular $\mathrm{C}\left(\mathrm{sp}^{3}\right)-\mathrm{H}$ insertion of nitrenes generated from either azides ${ }^{[14]}$ or hydroxylamine derivatives. ${ }^{[15]}$ Contrary to the other approaches, enantioselective versions of these nitrene transfers have recently been reported. ${ }^{[16]}$ These are rare examples of asymmetric pyrrolidines syntheses via a $\mathrm{C}-\mathrm{H}$ activation process that, however, display limitations in terms of yield ${ }^{[16 \mathrm{~b}]}$ or enantioselectivity. ${ }^{[16 a, c]}$

\section{Scheme 1.}

With the aim to develop an efficient access to substituted pyrrolidines, we envisioned the design of a novel strategy that would preclude the presence of a pre-installed nitrogen function. Thus, we wondered whether enantiopure pyrrolidines could be accessible from simple hydrocarbons via a 
streamlined two-step sequence. The latter consists in an asymmetric regioselective intermolecular nitrene $\mathrm{C}\left(\mathrm{sp}^{3}\right)-\mathrm{H}$ insertion with an enantiopure sulfonimidamide as a chiral auxiliary, followed by a diastereoselective cyclization involving a 1,5-HAT (Scheme 1b). In this manuscript, we wish to report the results of our studies. ${ }^{[17]}$

The first step of our approach relies on a catalytic intermolecular $\mathrm{C}\left(\mathrm{sp}^{3}\right)-\mathrm{H}$ amination reaction mediated by iodine(III) oxidants. ${ }^{[18]}$ Several methods have been developed to this end, but the use of rhodium(II) complexes in combination with sulfamates generally affords the best conversion in intermolecular $\mathrm{C}-\mathrm{H}$ amination. ${ }^{[19]}$ However, their application to 1,4-diarylbutane derivatives did not prove efficient both in terms of yields and selectivity (see Scheme S1, supporting information). Far more efficient was the stereoselective version developed with sulfonimidamides (Figure 2). ${ }^{20]}$ Whereas the method has been applied mostly to ethylarene derivatives so far, ${ }^{[1]}$ we were pleased to obtain the expected products from various complex substrates generally formed as single stereoisomers (See Table S1, supporting information).

\section{Figure 2.}

The reaction was first applied to symmetrical derivatives 7a-e. The yields in the $40-99 \%$ range underscore the influence of electronic factors on the course of the reaction. We capitalized on this observation to perform the regioselective functionalization of non-symmetrical analogs. The differentiation of both aromatic rings via the introduction of electron-donating or -withdrawing substituents led to selectively functionalize a single benzylic site. Accordingly, compounds 7i-k were converted in high yields (78-84\%) and excellent levels of regio- and stereocontrol. Moreover, similar results were obtained with substrates $\mathbf{7 f - h}$ for which steric factors - the presence of an ortho-substituent - are responsible for the complete regioselectivity. ${ }^{[21]}$ It is noteworthy that the reaction also efficiently applies to various butyl or hexyl derivatives (products 81-m) as well as to simple alkanes $(\mathbf{8 0}$ and $\mathbf{8 p})$. In the end, the stereoselective intermolecular $\mathrm{C}\left(\mathrm{sp}^{3}\right)-\mathrm{H}$ functionalization afforded $>15$ different precursors awaiting the second amination step to deliver enantiopure pyrrolidines.

Initial tests of cyclization from product $8 \mathbf{a}$ relied on light irradiation-based protocols reported by Suárez, ${ }^{[22]}$ Muñiz, ${ }^{[13 a]}$ and Nagib. ${ }^{[13 e]}$ However, they only gave 1:1 mixtures of cis:trans pyrrolidine 9a isolated in $\sim 20 \%$ yield in the presence of stoichiometric amounts of iodine sources. By contrast, the thermal conditions described by $\mathrm{Nagib}^{[13 \mathrm{e}]}$ proved more efficient as $\mathbf{9 a}$ was isolated in $58 \%$ yield but with a low d.r. of 1.2:1 (entry 1, table 1). Optimization of the conditions was envisaged with the aim to address the issue of diastereoselectivity, since diastereoselective Hofmann-LöfflerFreytag reactions are still rare in the literature. 


\section{Table 1.}

A screening of solvents (See Table S2, supporting information) revealed that the best yields were obtained in aromatic solvents and toluene was selected for the rest of the study (entry 2). We then investigated the influence of the hypervalent iodine reagent on the cyclization outcome. ${ }^{[23]}$ Several iodine(III) oxidants prepared from various iodoarene precursors or having different carboxylate ligands were tested (See Table S3, supporting information). The use of the reagent derived from 3chloro-1-iodobenzene and having $m \mathrm{CBA}$ ligands ( $m \mathrm{CBA}$ : meta-chlorobenzoate) led us to isolate compound 9a with a higher d.r. of 4.6:1 while preserving a good reactivity (entry 3). A similar observation was then made after the screening of the iodide source (See Table S4, supporting information). Indeed, we found that the stereoselectivity of the iodine-mediated cyclization was boosted in the presence of silver(I) iodide. The pyrrolidine 9a was obtained with a d.r. of 8:1 albeit with a lower yield of $30 \%$ (entry 4). Finally, optimal conditions were obtained by increasing the temperature $\left(90^{\circ} \mathrm{C}\right.$, entry 5$)$, tuning the amount of hypervalent iodine reagent and silver iodide to 4.3 equiv. (entry $6 v s$. entries 8-10), and working at a higher dilution $(\mathrm{c}=0.05 \mathrm{M}$, entry 7$)$.

These conditions were then successfully applied to all the compounds depicted in figure 2 to deliver the corresponding pyrrolidines 9a-p with good d.r. (Figure 3). Importantly, the trans and cis isomers, in the relevant cases, were separated and isolated as enantiopure products after chromatography on silica gel, the trans derivative being always predominantly formed with yields ranging from $41 \%$ to $70 \%$. This was corroborated by careful NMR experiments, and by the X-ray structures of the trans-products $9 \mathbf{9}$ and $\mathbf{9 j}$.

\section{Figure 2.}

Importantly, this sequence of two consecutive stereoselective $\mathrm{C}\left(\mathrm{sp}^{3}\right)-\mathrm{H}$ amination reactions led us to synthesize a variety of new 2,5-disubstituted pyrrolidines for which the preparative methods are scarce. These methods rely on the lengthy elaboration of 1,3-dicarbonyl compounds, ${ }^{[24]}$ the derivatization of pyroglutamic acid, ${ }^{[25]}$ or the direct functionalization of preformed pyrrolidines. ${ }^{[26]}$ Also worth of mention are the bridged nitrogen heterocycles $9 \mathrm{e}$ and $9 \mathbf{p}$ accessible in two steps from dibenzosuberane and cycloheptane, which are simplified analogues of the NMDA receptor antagonist MK-801 and tropane alkaloids, respectively. Finally, compound 9o highlights that a simple alkane such as 2-methylpentane can be used as starting materials for the synthesis of heterocycles.

Several test experiments were performed to investigate the mechanism of the intramolecular $\mathrm{C}\left(\mathrm{sp}^{3}\right)-\mathrm{H}$ amination reaction of amides 8 (Scheme 2). First, the starting material was recovered 
unreacted in the presence of the radical inhibitor BHT, a result that supports the involvement of a radical pathway. Then, we studied the reactivity of haloamines that are generated in the reaction. ${ }^{[13]}$ Because $N$-iodoamides are too unstable to be isolated, we decided to prepare the analogous chloroamine $\mathbf{1 0}$ that could be obtained from $\mathbf{8 a}$ by reaction with trichloroisocyanuric acid. Pleasingly, compound $\mathbf{1 0}$ was transformed to the expected pyrrolidine $\mathbf{9 a}$ in good yield by combining $\mathrm{AgI}$ with $3-\mathrm{ClC}_{6} \mathrm{H}_{4} \mathrm{I}(m \mathrm{CBA})_{2}$ in toluene at $90{ }^{\circ} \mathrm{C}$. Additional experiments revealed that moderate conversions and lower yields are obtained in the sole presence of AgI or the hypervalent iodine reagent. These results clearly highlight a synergistic effect of both reagents on the efficiency of the overall process. Surprisingly, the reaction with the hypervalent iodine reagent alone afforded the trans isomer with full selectivity, whereas a much lower d.r. was obtained in its absence. These significant changes in the diastereoselectivity depending on the conditions suggest that several competing mechanisms might operate during the cyclization. These observations led to a mechanistic proposal that involves the initial formation of a $N$-centered radical from the iodoamine, followed by a 1,5-Hydrogen Atom Transfer. From the resulting benzylic radical, two scenarios could operate. It could be trapped to afford the corresponding iodide. Then, a stereospecific $\mathrm{S}_{\mathrm{N}} 2-$ type cyclization would deliver the pyrrolidine 9a with a low d.r. because the trapping of the benzylic radical remote from the stereogenic center is expected to proceed with a low diastereocontrol. Alternatively, the radical could be oxidized by the hypervalent iodine reagent to a carbocation that could undergo a $\mathrm{S}_{\mathrm{N}} 1$-type cyclization proceeding with high diastereocontrol. ${ }^{[27]}$ Thus, the overall d.r. would be the result of the simultaneous occurrence of both mechanisms for the cyclization, and the use of highly soluble $3-\mathrm{ClC}_{6} \mathrm{H}_{4} \mathrm{I}(m \mathrm{CBA})_{2}$ is key to achieve good selectivity. ${ }^{[28]}$

\section{Scheme 2.}

Final experiments were aimed at removing the sulfonimidoyl group to isolate the free $\mathrm{NH}$ pyrrolidines (Scheme 3). Use of magnesium in dry methanol under sonication allowed us to isolate pyrrolidines 11 and 12 in $66 \%$ and $76 \%$ yields, respectively. ${ }^{[29]}$

\section{Scheme 3.}

In conclusion, chiral disubstituted pyrrolidines are accessible in only two steps in an enantiopure form from simple hydrocarbons used as the limiting component. The strategy relies on two consecutive $\mathrm{C}\left(\mathrm{sp}^{3}\right)-\mathrm{H}$ amination reactions involving a catalytic stereoselective nitrene insertion then a diastereoselective HLF-type cyclization. Worthy of note is the straightforward access to nonsymmetrical disubstituted products that could provide new scaffolds for the design of chiral organocatalysts or organometallic complexes. This sequence was ultimately applied to alkanes 
making these broadly available compounds useful building blocks for the synthesis of heterocycles. Work is in progress to investigate application of our strategy to the synthesis of new pyrrolidines as useful tools in catalysis.

\section{Acknowledgements}

We wish to thank the French National Research Agency (program n ANR-11-IDEX-0003-02 and CHARMMMAT ANR-11-LABX-0039; fellowship to Y. L.), the COMUE Université Paris-Saclay (program IDEX Paris/Saclay CDE-2018-002093; fellowship to Y. L.), and the ICSN for their support.

\section{References}

[1] Pyrrolidines belong to the top 5 most frequent nitrogen heterocycles in the U.S. FDA approved drugs. E. Vitaku, D. T. Smith, J. T. Njardarson, J. Med. Chem. 2014, 57, 10257.

[2] J. J. Feld, K. V. Kowdley, E. Coakley, S. Sigal, D. R. Nelson, D. Crawford, O. Weiland, H. Aguilar, J. Xiong, T. Pilot-Matias, B. DaSilva-Tillmann, L. Larsen, T. Podsadecki, B. Bernstein, N. Engl. J. Med. 2014, 370, 1594.

[3] a) Y. H. Choi, J. Y. Choi, H. Y. Yang, Y. H. Kim, Tetrahedron: Asymmetry 2002, 13, 801; b) M. Fananas-Mastral, M. Pérez, P. H. Bos, A. Rudolph, S. R. Harutyunyan, B. L. Feringa, Angew. Chem. Int. Ed. 2012, 51, 1922; Angew. Chem. 2012, 124, 1958.

[4] E. K. Kemppainen, G. Sahoo, A. Piisola, A. Hamza, B. Kotai, I. Papai, P. M. Pikho, Chem. Eur. J. 2014, 20, 5983.

[5] J. K. Whitesell, Chem. Rev. 1989, 89, 1581.

[6] S. Lee, H. Lei, T. Rovis, J. Am. Chem. Soc. 2019, 141, 12536. See reference 3.

[7] P.-Q. Huang in Asymmetric Synthesis of Nitrogen Heterocycles, (Ed.: J. Royer), Wiley-VCH, Weinheim, 2009, pp. 51-94.

[8] For some recent asymmetric strategies, see: a) K. R. Campos, A. Klapars, J. H. Waldman, P. G. Dormer, C. Y. Chen, J. Am. Chem. Soc. 2006, 128, 3538; b) G.-H. Hou, J.-H. Xie, P.-C. Yan, Q.-L. Zhou, J. Am. Chem. Soc. 2009, 131, 1366; c) B. M. Trost, S. M. Silverman, J. Am. Chem. Soc. 2012, 134, 4941; d) A. R. Brown, C. Uyeda, C. A. Brotherton, E. N. Jacobsen, J. Am. Chem. Soc. 2013, 135, 6747; e) M. Jäkel, J. Qu, T. Schnitzer, G. Helmchen, Chem. Eur. J. 2013, 19, 16746; f) X.j. Dai, O. D. Engl, T. Léon, S. L. Buchwald, Angew. Chem. Int. Ed. 2019, 58, 3407; Angew. Chem. 2019, 131, 3445.

[9] a) K. Godula, D. Sames, Science 2006, 312, 67; b) J. Yamaguchi; A. D. Yamaguchi, K. Itami, Angew. Chem. Int. Ed. 2012, 51, 8960; Angew. Chem. 2012, 124, 9092; c) D. J. Abrams, P. A. Provencher, E. N. Sorensen, Chem. Soc. Rev. 2018, 47, 8925; d) O. Baudoin, Angew. Chem. Int. Ed. 2020, 59, 17798; Angew. Chem. 2020, 132, 17950. 
[10] M. Zhang, Q. Wang, Y. Peng, Z. Chen, C. Wan, J. Chen, Y. Zhao, R. Zhang, A. Q. Zhang, Chem. Commun. 2019, 55, 13048.

[11] a) E. T. Nadres, O. Daugulis, J. Am. Chem. Soc. 2012, 134, 7; b) G. He, Y. Zhao, S. Zhang, C. Lu, G. Chen, J. Am. Chem. Soc. 2012, 134, 3; c) M. Yang, B. Su, Y. Wang, K. Chen, X. Jiang, Y.-F. Zhang, X.-S. Zhang, G. Chen, Y. Cheng, Z. Cao, Q.-Y. Guo, L. Wang, Z.-J. Shi, Nat. Commun. 2014, 5, 4707.

[12] a) A. W. Hoffmann, Chem. Ber. 1883, 16, 558; b) K. Löffler, C. Freytag, Chem. Ber. 1909, 42, 3427.

[13] a) C. Martinez, K. Muñiz, Angew. Chem. Int. Ed. 2015, 54, 8287; Angew. Chem. 2015, 127, 8405; b) P. Becker, T. Duhamel, C. J. Stein, M. Reiher, K. Muñiz, Angew. Chem. Int. Ed. 2017, 56, 8004; Angew. Chem. 2017, 129, 8117; c) P. Becker, T. Duhamel, C. Martinez, K. Muñiz, Angew. Chem. Int. Ed. 2018, 57, 5166; Angew. Chem. 2018, 130, 5262; d) T. Duhamel, C. J. Stein, C. Martinez, M. Reiher, K. Muñiz, ACS Catal. 2018, 8, 3918; e) N. R. Paz, D. Rodríguez-Sosa, H. Valdés, R. Marticorena, D. Melián, M. Belén Copano, C. C. Gonzalez, A. J. Herrera, Org. Lett. 2015, 17, 2370; f) E. A. Wappes, S. C. Fosu, T. C. Chopko, D. A. Nagib, Angew. Chem. Int. Ed. 2016, 55, 9974; Angew. Chem. 2016, 128, 10128; g) F. Wang, S. S. Stahl, Angew. Chem. Int. Ed. 2019, 58, 6385; Angew. Chem. 2019, 131, 6451; h) D. Meng, Y. Tang, J. Wei, X. Shi, M. Yang, Chem. Commun. 2017, 53, 5744; i) M. C. Lux, J. Jurczyk, Y.-H. Lam, Z. J. Song, C. Ma, J. B. Roque, J. S. Ham, N. Sciammetta, D. Adpressa, R. Sarpong, C. S. Yeung, Org. Lett. 2020, 22, 6578; j) R.-X. Jin, J.-C. Dai, Y. Li, X.-S. Wang, Org. Lett. 2021, 23, 421. For reviews, see: k) M. Nechab, S. Mondal, M. P. Bertrand, Chem. Eur. J. 2014, 20, 16034; 1) L. M. Stateman, K. M. Nakafuku, D. A. Nagib, Synthesis 2018, 50, 1569.

[14] a) E. T. Hennessy, T. A. Betley, Science 2013, 3407, 5915; b) D. A. Iovan, M. J. T. Wilding, Y. Baek, E. T. Hennessy, T. A. Betley, Angew. Chem. Int. Ed. 2017, 56, 15599; Angew. Chem. 2017, 129, 15805; c) Y. Dong, R. M. Clarke, G. J. Porter, T. A. Betley, J. Am. Chem. Soc. 2020, 142, 10996; d) N. C. Thacker, Z. Lin, T. Zhang, J. C. Gilhula, C. W. Abney, W. Lin, J. Am. Chem. Soc. 2016, 138, 3501; e) B. Bagh, D. L. J. Broere, V. Sinha, P. F. Kuijpers, N. P. Van Leest, B. de Bruin, S. Demeshko, M. A. Siegler, J. I. van der Vlugt, J. Am. Chem. Soc. 2017, 139, 5117; f) I. T Alt, C. Guttroff, B. Plietker, Angew. Chem. Int. Ed. 2017, 56, 10582; Angew. Chem. 2017, 129, 10718; g) K.-P. Shing, Y. Liu, B. Cao, X.-Y. Chang, T. You, C.-M. Che, Angew. Chem. Int. Ed. 2018, 57, 11947; Angew. Chem. 2018, 130, 12123; h) K.-P. Shing, Y. Liu, B. Cao, X.-Y. Chang, C.-M. Che, Org. Lett. 2019, 21, 895.

[15] a) S. Munnuri, A. M. Adebesin, M. P. Paudyal, M. Yousufuddin, A. Dalipe, J. R. Falck, J. Am. Chem. Soc. 2017, 139, 18288; b) H. Noda, Y. Asuda, M. Shibasaki, Org. Lett. 2020, 22, 8769.

[16] a) P. F. Kuijpers, M. J. Tiekink, W. B. Breukelaar, D. L. J. Broere, N. P. Van Leest, J. I. van der Vlugt, J. N. H. Reek, B. de Bruin, Chem. Eur. J. 2017, 23, 7945; b) J. Qin, Z. Zhou, T. Cui, M. Hemming, E. Meggers, Chem. Sci. 2019, 10, 3202; c) Y. Dong, C. J. Lund, G. J. Porter, R. M. Clarke, S.-L. Zheng, T. R. Cundari, T. A. Betley, J. Am. Chem. Soc. 2021, 143, 817. For a different strategy based on the asymmetric $\alpha-C-\mathrm{H}$ arylation of pyrrolidines, see: d) P. Jain, P. Verma, G. Xia, J.-Q. Yu, Nat. Chem. 2017, 9, 140.

[17] A two-step synthesis of pyrrolidines from alkylbenzenes has recently been reported by application of radical chemistry. The reactions afford racemic products as mixtures of diastereoisomers. See: a) F. Wu, 
J. P. Ariyarathna, N. Kaur, M. L. Kennell, O. H. Bassiouni, W. Li, Org. Lett. 2020, 22, 2135; b) A. E. Bosnidou, K. Muñiz, Angew. Chem. Int. Ed. 2019, 58, 7485; Angew. Chem. 2019, 131, 7564.

[18] For reviews, see: a) P. Müller, C. Fruit, Chem. Rev. 2003, 103, 2905; b) J. W. W. Chang, T. M. U. Ton, P. W. H. Chan, Chem. Rec. 2011, 11, 331; c) J. L. Roizen, M. E. Harvey, J. Du Bois, J. Acc. Chem. Res. 2012, 45, 911; d) J. Buendia, G. Grelier, P. Dauban, Adv. Organomet. Chem. 2015, 64, 77; e) J. M. Alderson, J. R. Corbin, J. M. Schomaker, Acc. Chem. Res. 2017, 50, 2147; f) D. Hazelard, P.-A. Nocquet, P. Compain, Org. Chem. Front. 2017, 4, 2500.

[19] For relevant studies, see: a) K. W. Fiori, J. Du Bois, J. Am. Chem. Soc. 2007, 129, 562; b) J. L. Roizen, D. N. Zalatan, J. Du Bois, Angew. Chem. Int. Ed. 2013, 52, 11343; Angew. Chem. 2013, 125, 11553; c) N. D. Chiappini, J. B. C. Mack, J. Du Bois, Angew. Chem. Int. Ed. 2018, 57, 4956; Angew. Chem. 2018, 130, 5050; d) A. Nasrallah, V. Boquet, A. Hecker, P. Retailleau, B. Darses, P. Dauban, Angew. Chem. Int. Ed. 2019, 58, 8192; Angew. Chem. 2019, 131, 8276; e) A. Nasrallah, Y. Lazib, V. Boquet, B. Darses, P. Dauban, Org. Process. Res. Dev. 2020, 24, 724; f) E. Brunard, V. Boquet, E. Van Elslande, T. Saget, P. Dauban, J. Am. Chem. Soc. 2021, 143, 6407.

[20] a) C. Liang, F. Robert-Peillard, C. Fruit, P. Müller, R. H. Dodd, P. Dauban, Angew. Chem. Int. Ed. 2006, 45, 4641; Angew. Chem. 2006, 118, 4757; b) C. Liang, F. Collet, F. Robert-Peillard, P. Müller, R. H. Dodd, P. Dauban, J. Am. Chem. Soc. 2008, 130, 343; c) F. Collet, C. Lescot, C. Liang, P. Dauban, Dalton Trans. 2010, 39, 10401; d) B. Darses, A. G. Jarvis, A.-K. Mafroud, G. Estenne-Bouhtou, G. Dargazanli, P. Dauban, Synthesis 2013, 45, 2079.

[21] J. Buendia, B. Darses, P. Dauban, Angew. Chem. Int. Ed. 2015, 54, 5697; Angew. Chem. 2015, 127, 5789; b) J. Buendia, G. Grelier, B. Darses, A. G. Jarvis, F. Taran, P. Dauban, Angew. Chem. Int. Ed. 2016, 55, 7530; Angew. Chem. 2016, 128, 7656.

[22] P. De Armas, R. Carrau, J. I. Concepción, C. G. Francisco, R. Hernández, E. Suárez, Tetrahedron Lett. 1985, 26, 2493.

[23] An initial experiment with $\mathrm{PhI}(\mathrm{OPiv})_{2}$ led to a lower yield of $35 \%$ while no reaction occurred in the presence $\mathrm{PhIO}$ or $\mathrm{PhI}\left(\mathrm{OCOCF}_{3}\right)_{2}$.

[24] a) J. M. Chong, I. S. Clarke, I. Koch, P. C. Olbach, N. J. Taylor, Tetrahedron:Asymmetry 1995, 6, 409;

b) D. J. Aldous, W. M. Dutton, P. G. Steel, Tetrahedron:Asymmetry 2000, 11, 2455.

[25] a) B. M. Trost, D. A. Thaisrivongs, E. J. Donckele, Angew. Chem. Int. Ed. 2013, 52, 1523; Angew. Chem. 2013, 125, 1563; b) A. Claraz, G. Sahoo, D. Berta, A. Madarász, I Pápai, P. M. Pikho, Angew. Chem. Int. Ed. 2016, 55, 669; Angew. Chem. 2016, 128, 679; c) S. Kortet, A. Claraz, P. M. Pikho, Org. Lett. 2020, 22, 3010.

[26] B. M. Trost, S. M. Silverman, J. P. Stambuli, J. Am. Chem. Soc. 2011, 133, 19483.

[27] This mechanistic proposal does not apply to non-benzylic radicals, as in the case of compound 91 for which a lower d.r. is observed.

[28] This proposal is in line with an additional experiment performed from haloamine $\mathbf{1 0}$ in the presence of $\mathrm{AgCl}$ and the iodine(III) oxidant. The resulting trans-pyrrolidine 9a was isolated in $49 \%$ and an excellent d.r. of $>20: 1$. We believe that these conditions induce the formation of a benzylic chloride 
from which the $\mathrm{S}_{\mathrm{N}} 2$-type cyclization would be disfavored, hence the sole $\mathrm{S}_{\mathrm{N}} 1$-type mechanism would operate.

[29] The racemic trans-pyrrolidine 11 was prepared according to the protocol reported by Seidel et al. (See: W. Chen, L. Ma, A. Paul, D. Seidel, Nat. Chem. 2017, 10, 165). Then, application of the method reported by Pihko et al. (see ref. 25b) that involves the derivatization of 2,5-diarylpyrrolidines to phosphoramidites, led us to determine that the $(R, R)$-pyrrolidine 11 was obtained with an e.r. of $>98: 2$. 


\section{Legends for schemes and tables:}

Figure 1. Relevant examples of 2,5-substituted pyrrolidines.

Figure 2. Regio- and stereoselective intermolecular $\mathrm{C}\left(\mathrm{sp}^{3}\right)-\mathrm{H}$ amination of hydrocarbons; d.r. and r.r. are reported for isolated compounds. [a] 5.0 equiv. of substrate.

Figure 3. Stereoselective intramolecular $\mathrm{C}\left(\mathrm{sp}^{3}\right)-\mathrm{H}$ amination for the formation of pyrrolidines. ${ }^{[a]} \mathrm{AgI}$ was replaced by $\mathrm{CuI}$.

Scheme 1. C-H functionalization reactions for the syntheses of pyrrolidines.

Scheme 2. Mechanistic investigations.

Scheme 3. Deprotection of the $N$-(sulfonimidoyl)pyrrolidines.

Table 1. Screening of conditions for the stereoselective cyclization. ${ }^{[a]}$ 


\section{Table 1.}

\begin{tabular}{|c|c|c|c|c|c|}
\hline Entry & $\begin{array}{l}\text { Iodine source } \\
\text { (equiv.) }\end{array}$ & $\begin{array}{l}\text { Hypervalent iodine } \\
\text { (equiv.) }\end{array}$ & Solvent & Yield $^{[b]}$ & d.r. ${ }^{[c]}$ \\
\hline 1 & $\mathrm{NaI}(4.0)$ & $\mathrm{PhI}(\mathrm{OAc})_{2}(4.0)$ & $\mathrm{MeCN}$ & 58 & $1.2: 1$ \\
\hline 2 & $\mathrm{NaI}(4.0)$ & $\mathrm{PhI}(\mathrm{OAc})_{2}(4.0)$ & Toluene & 75 & $2: 1$ \\
\hline 3 & $\mathrm{NaI}(4.0)$ & $3-\mathrm{ClC}_{6} \mathrm{H}_{4} \mathrm{I}(m \mathrm{CBA})_{2}(4.0)$ & Toluene & 76 & $4.6: 1$ \\
\hline 4 & $\mathrm{AgI}(4.0)$ & $3-\mathrm{ClC}_{6} \mathrm{H}_{4} \mathrm{I}(m \mathrm{CBA})_{2}(4.0)$ & Toluene & 30 & $8: 1$ \\
\hline $5^{[\mathrm{d}]}$ & AgI (4.0) & $3-\mathrm{ClC}_{6} \mathrm{H}_{4} \mathrm{I}(m \mathrm{CBA})_{2}(4.0)$ & Toluene & 61 & $8: 1$ \\
\hline $6^{[\mathrm{d}]}$ & AgI (4.3) & $3-\mathrm{ClC}_{6} \mathrm{H}_{4} \mathrm{I}(m \mathrm{CBA})_{2}$ & Toluene & 65 & $8: 1$ \\
\hline $7^{[\mathrm{d}, \mathrm{e}]}$ & AgI (4.3) & $3-\mathrm{ClC}_{6} \mathrm{H}_{4} \mathrm{I}(m \mathrm{CBA})_{2}(4.3)$ & Toluene & 71 & $8: 1$ \\
\hline $8^{[\mathrm{d}, \mathrm{e}]}$ & $\operatorname{AgI}(5.0)$ & $3-\mathrm{ClC}_{6} \mathrm{H}_{4} \mathrm{I}(m \mathrm{CBA})_{2}(5.0)$ & Toluene & 72 & $8: 1$ \\
\hline $9^{[\mathrm{d}, \mathrm{e}]}$ & $\operatorname{AgI}(3.0)$ & $3-\mathrm{ClC}_{6} \mathrm{H}_{4} \mathrm{I}(m \mathrm{CBA})_{2}(5.0)$ & Toluene & 46 & $7.5: 1$ \\
\hline $7^{[\mathrm{d}, \mathrm{e}]}$ & $\operatorname{AgI}(4.3)$ & $3-\mathrm{ClC}_{6} \mathrm{H}_{4} \mathrm{I}(m \mathrm{CBA})_{2}(3.0)$ & Toluene & 39 & $7: 1$ \\
\hline
\end{tabular}

[a] Reaction conditions: A mixture of $\mathbf{8 a}(0.10 \mathrm{mmol})$, iodine source and

hypervalent iodine reagent in toluene is stirred $(1 \mathrm{~mL})$ at $65^{\circ} \mathrm{C}$ for $48-72 \mathrm{~h}$.

[b] After flash chromatography.

[c] Determined by ${ }^{1} \mathrm{H}$ NMR of crude reaction mixture.

[d] Run at $90^{\circ} \mathrm{C}$

$[\mathrm{e}] \mathrm{c}=0.05 \mathrm{M}$. 


\section{Suggested text for the table of contents:}

Simple hydrocarbons such as alkanes are shown to be useful building blocks for the asymmetric synthesis of heterocycles. They are converted in only two steps to pyrrolidines by application of stereoselective $\mathrm{C}\left(\mathrm{sp}^{3}\right)-\mathrm{H}$ amination reactions. Symmetrical and non-symmetrical enantiopure 2,5disubstituted pyrrolidines are isolated in good yields.

\section{Keywords:}

Pyrrolidine $\bullet \mathrm{C}-\mathrm{H}$ Amination $\bullet$ Nitrene $\bullet$ Haloamine $\bullet$ Stereoselectivity 


\section{Graphics:}

\section{Graphical abstract}

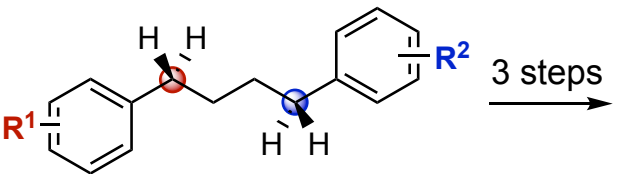

Hydrocarbons as the limiting component<smiles>[R14]c1ccc([C@@H]2CC[C@@H](C)N2)cc1</smiles>

Enantiopure trans-pyrrolidine
- Excellent regio- and stereocontrol - Application to simple alkanes

- Access to non-symmetrical analogs

- Easy access to free pyrrolidines 
Figure Table 1

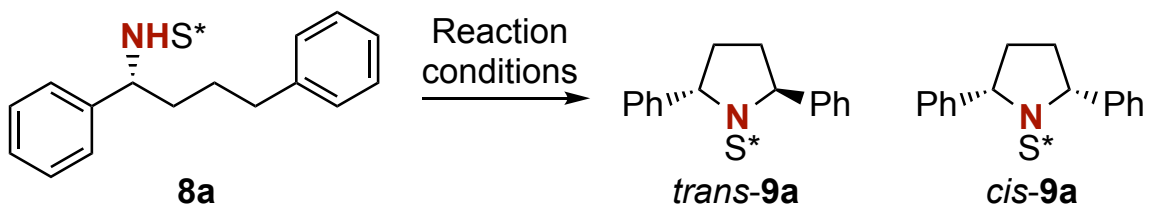




\section{Scheme 1}

1a. Previous syntheses of pyrrolidines by $\mathrm{C}-\mathrm{H}$ functionalization reactions

Formation of pyrrolidines by a CMD process ${ }^{[11]}$

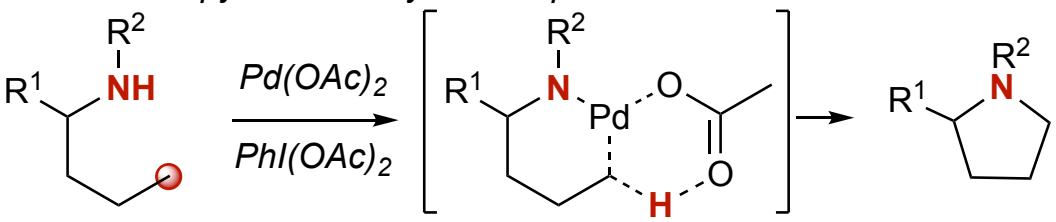

Formation of pyrrolidines by $1,5-H A T^{[12,13]}$

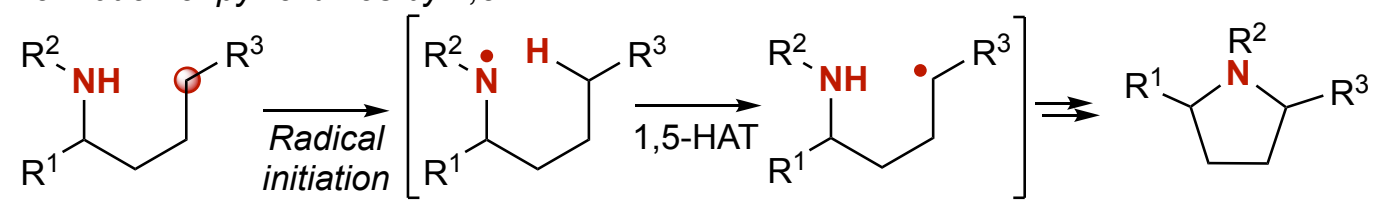

Formation of pyrrolidines by catalytic intramolecular nitrene $\mathrm{C}-\mathrm{H}$ insertion ${ }^{[14,15]}$

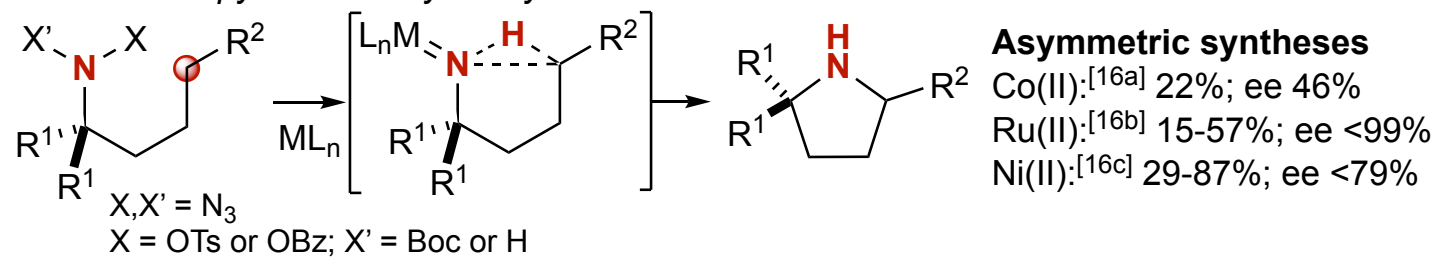

1b. This work: Stereoselective synthesis by sequential $C\left(s p^{3}\right)-H$ amination reactions

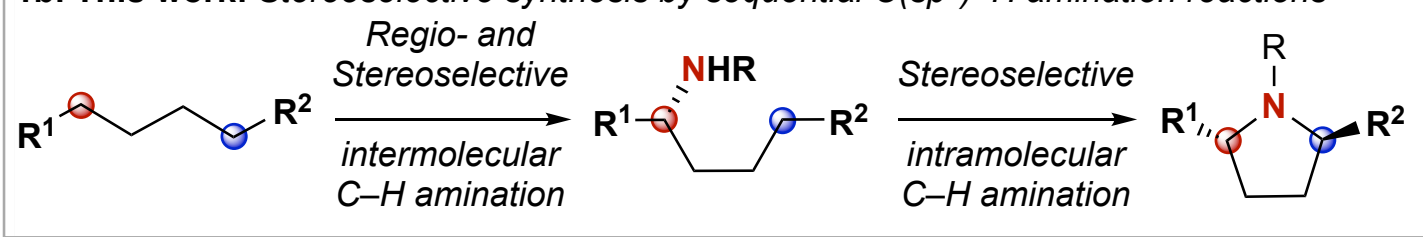




\section{Scheme 2}

Reaction with a radical inhibitor

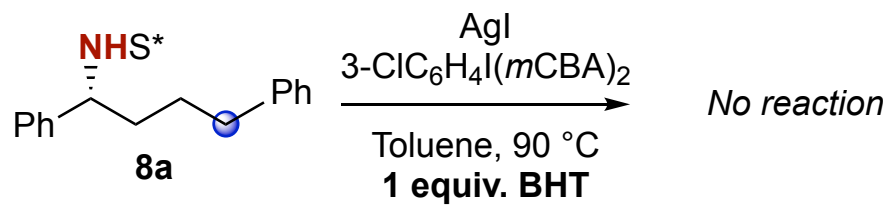

Preparation of the chloramine $\mathbf{1 0}$ from $\mathbf{8 a}$, and its reaction under different conditions

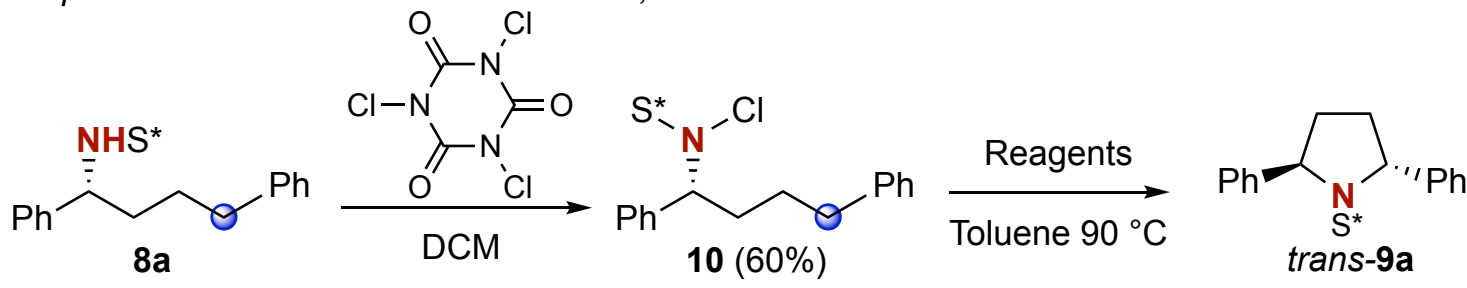

1. $\mathrm{Agl}, 3-\mathrm{ClC}_{6} \mathrm{H}_{4} \mathrm{I}(m \mathrm{CBA})_{2}: 61 \%$, d.r. $\sim 5: 1$

2. Agl: $28 \%$, d.r. $\sim 3: 1$

Mechanistic proposal

3. $3-\mathrm{ClC}_{6} \mathrm{H}_{4} \mathrm{I}(m \mathrm{CBA})_{2}: 30 \%$, d.r. $>20: 1$

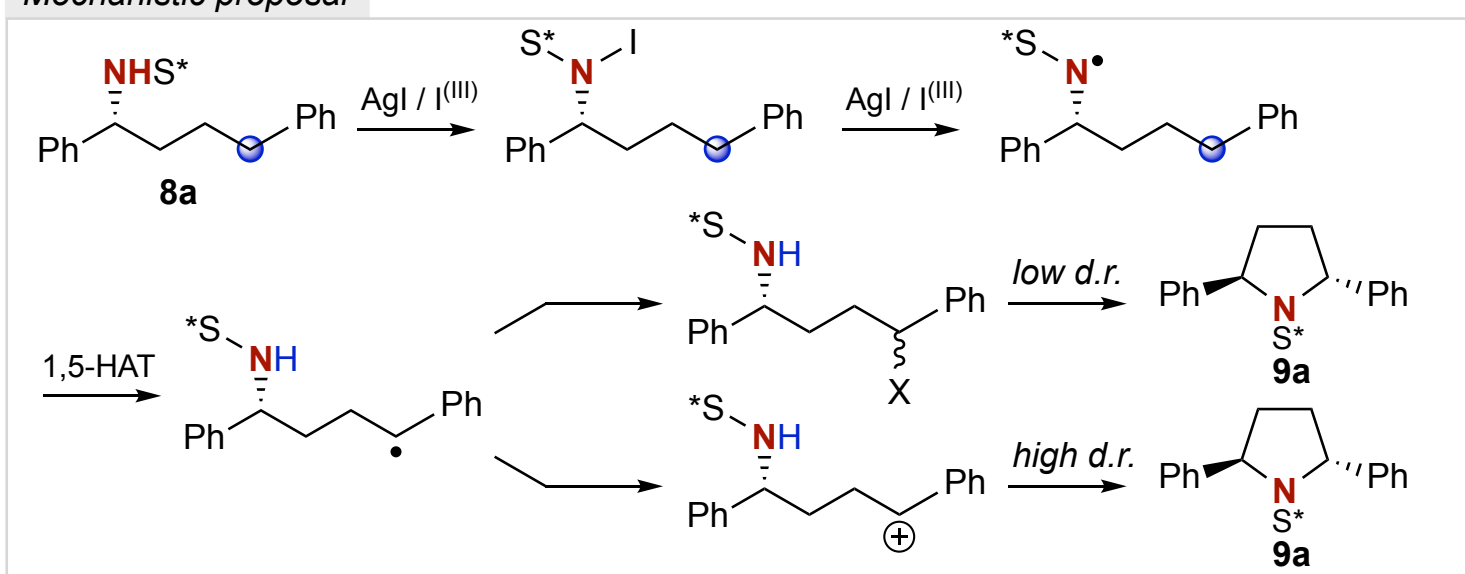




\section{Scheme 3}
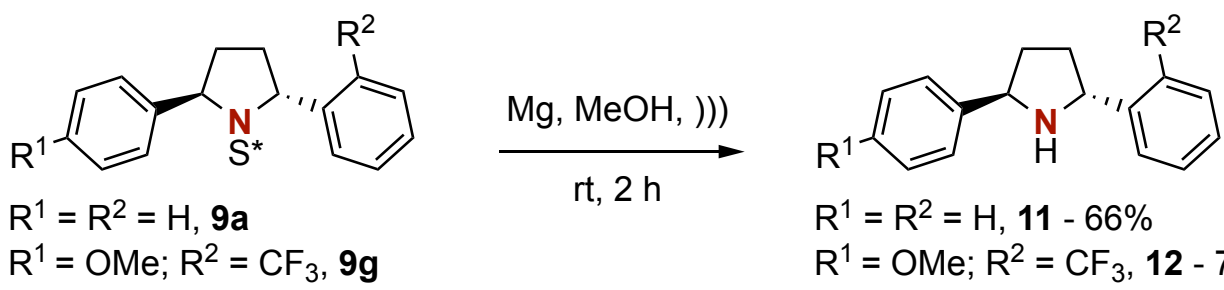

$\mathrm{R}^{1}=\mathrm{OMe} ; \mathrm{R}^{2}=\mathrm{CF}_{3}, 12-76 \%$ 
Figure 1

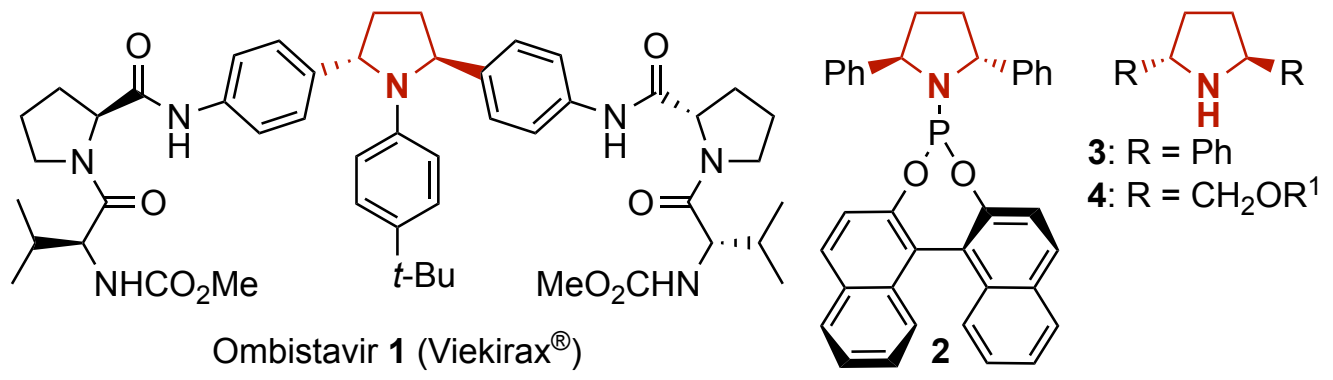


Figure 2

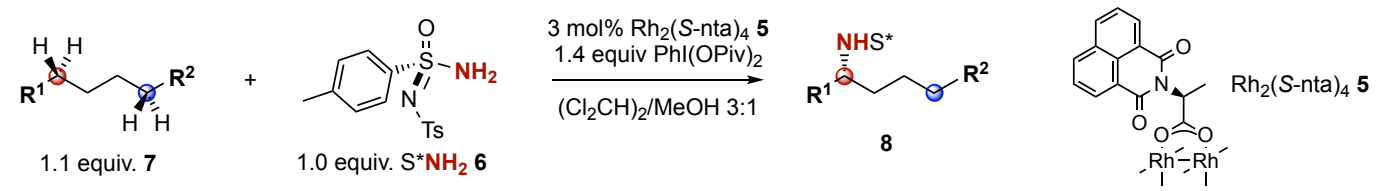

Symmetrical substrates

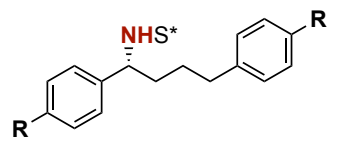

$\mathbf{R}=\mathbf{H} \quad$ 8a: $65 \%$; d.r. $>20: 1$

$\mathbf{R}=$ OMe 8b: $91 \%$; d.r. $>20: 1$

$\mathbf{R}=\mathbf{C F}_{3} \quad$ 8c: $40 \% ;$ d.r. $>20: 1$

$\mathbf{R}=\mathbf{M e} \quad \mathbf{8 d}: 85 \% ;$ d.r. $>20: 1$

*SHN,

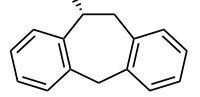

8e: $99 \%$; d.r. $>20: 1$
Non-symmetrical substrates

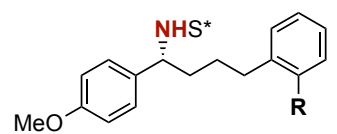

$\mathbf{R}=$ OMe 8f: $85 \%$; d.r. $90: 10$; r.r. $>20: 1$

$\mathbf{R}=\mathbf{C F}_{3} \quad 8 \mathrm{~g}: 80 \%$; d.r. $92: 8$; r.r. $>20: 1$

$\mathbf{R}=\mathbf{B r} \quad 8$ h: $83 \%$; d.r. 90:10; r.r. $>20: 1$

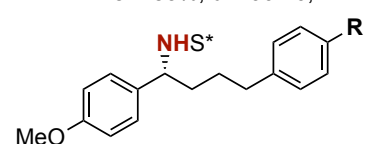

$\mathrm{MeO}^{-}$

$\mathbf{R}=\mathbf{C F}_{3} \quad \mathbf{8 i}: 78 \% ;$ d.r. $>20: 1 ;$ r.r. $8: 1$

$\mathbf{R}=\mathbf{C N} \quad \mathbf{8 j}: \mathbf{8 2} \%$; d.r. $>20: 1 ;$ r.r. $15: 1$

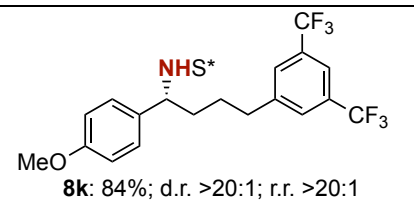

8k: $84 \%$; d.r. $>20: 1$; r.r. $>20: 1$

NHS*

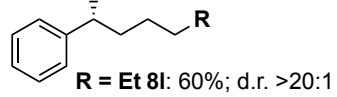

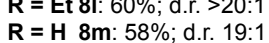

$\mathrm{NHS}^{*}$

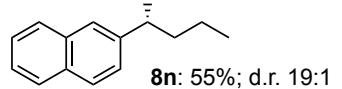

Alkanes

NHS*<smiles>CCCC(C)(C)C</smiles>

8o: $50 \%$ [a]

NHS*

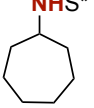

8p: $76 \%$ 
Figure 3

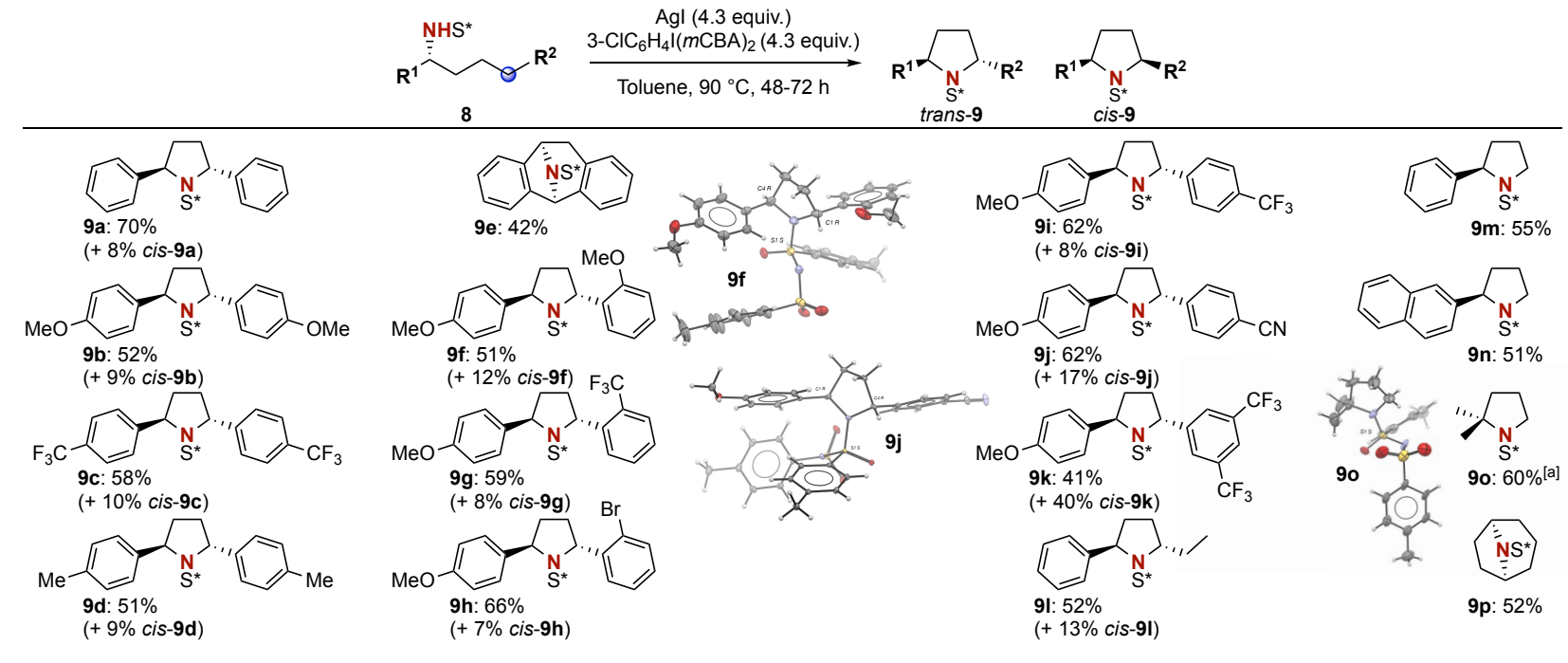

